\title{
PENERAPAN TRI-N DALAM BUKU TEKS SISWA BAHASA INDONESIA UNTUK SISWA SMP KELAS VIII KURIKULUM 2013
}

\author{
Siti Rahayu ${ }^{1} \&$ Siti Rochmiyati ${ }^{2}$ \\ 1,2 Program Studi Pendidikan Bahasa dan Sastra Indonesia, UST Yogyakarta \\ Jln. Batikan, Tahunan, Kec. Umbulharjo, Kota Yogyakarta, \\ Daerah Istimewa Yogyakarta 55167, Indonesia \\ Email: sityrahayu21@gmail.com ${ }^{1}$,rochmiyati_atik@ustjogja.ac.id ${ }^{2}$
}

Submitted: 14- October -2019

Accepted : 25-December-2019
Published: 26-December-2019

DOI: https://doi.org/10.31540/silamparibisa.v2i2 URL: https://doi.org/10.31540/silamparibisa.v2i2.594

\begin{abstract}
Abstrak
Tujuan penelitian ini adalah untuk mendeskripsikan penerapan proses Niteni, Nirokke, dan Nambahi pada buku teks siswa Bahasa Indonesia untuk Siswa SMP Kelas VIII Kurikulum 2013. Metode penelitian menggunakan metode deskriptif kualitatif dengan model analisis interaktif Miles dan Huberman. Teknik pengumpulan data menggunakan teknik dokumentasi yang bersumber dari buku teks siswa yaitu buku Bahasa Indonesia untuk Siswa SMP Kelas VIII Kurikulum 2013. Data pada penelitian ini adalah kata, frasa, kalimat, dan paragraf yang memuat kata kerja operasional dalam penerapan proses niteni, nirokke, dan nambahi yang terdapat pada buku teks siswa. Uji keabsahan data menggunakan membercheck dan validasi pakar. Teknik analisis data dengan langkah-langkah berikut: reduksi data, sajian data, dan verifikasi atau simpulan. Hasil penelitian menunjukkan bahwa semua indikator proses niteni, nirokke, dan nambahi terdapat dalam buku teks. Niteni dalam buku teks siswa terdapat unsur mengamati menggunakan indra pendengaran, menggali informasi lebih dalam dari hasil pengamatan, dan menalar dengan menghubungkan pengetahuan yang sudah dimiliki dari hasil galian. Nirokke dalam buku teks siswa terdapat unsur menirukan dengan melafalkan melalui suara, menirukan dengan membaca, menirukan dengan menulis, menirukan melalui gerakan, menirukan dengan mencoba atau eksperimen, menirukan dengan mendemonstrasikan atau mempraktikkan, dan menirukan dengan menyajikan. Kemudian, Nambahi dalam buku teks siswa terdapat unsur menambahi dengan mencipta atau membuat, dan proses menambahi dengan mengimprovisasi.
\end{abstract}

Kata kunci: Niteni, Nirokke, Nambahi, Buku Teks Bahasa Indonesia

\section{IMPLEMENTATION OF TRI-N IN INDONESIAN LANGUAGE TEXTBOOKS FOR 2013 GRADE VIII JUNIOR HIGH SCHOOL STUDENTS CURRICULUM}

\begin{abstract}
The purpose of this study was to describe the application of the Niteni, Nirokke, and Nambahi processes in Indonesian Students' Textbooks for Class VIII Junior High School Students in 2013 Curriculum. The research method uses a qualitative descriptive method with the interactive analysis model of Miles and Huberman. Data collection techniques using documentation techniques sourced from students' textbooks, namely Indonesian Language Books for Students of Class VIII Middle School Curriculum 2013. Data in this study are words, phrases, sentences, and paragraphs that contain operational verbs in the application of the niteni, nirokke, and nambahi to the student textbook. Test the validity of the data using member check and expert validation. Data analysis techniques with the following steps: data reduction, data presentation, and verification or conclusion. The results showed that all indicators of the
\end{abstract}


niteni, nirokke, and nambahi processes were contained in the textbook. Niteni in students' textbooks has the element of observing using the sense of hearing, digging deeper information from observations, and reasoning by connecting knowledge already possessed from excavated results. Nirokke in students' textbooks has the elements of imitating through sound, imitating by reading, imitating by writing, imitating through movement, imitating by trying or experimenting, imitating by demonstrating or practicing, and imitating by presenting. Then, Nambahi in student textbooks there is an element of adding by creating or making, and the process of adding by improvising.

Keywords: Niteni, Nirokke, Nambahi, Indonesian Textbooks

\section{A. Pendahuluan}

Pendidikan berkualitas suatu bangsa ditunjukkan seberapa kreatif guru dalam mengelola kelas dengan baik sehingga menciptakan siswa yang berpikir kritis, kreatif, kolaboratif, dan komunikatif (Noermanzah \& Friantary, 2019:6631). Keterampilan dalam mengelola kelas ini salah satunya dengan penggunaan buku teks yang tepat (Nugroho \& Fitri, 2018:117 \& Haslinda, 2017:48). Hal ini sesuai dengan salah satu tugas pendidik yaitu mampu menyusun bahan ajar yang menarik dan inovatif (Noermanzah, 2015:274). Buku teks terdiri atas buku guru dan buku siswa. Buku teks dijadikan sebagai pedoman pembelajaran oleh siswa dan merupakan salah satu faktor yang akan menentukan tingkat keberhasilan sebuah pembelajaran yang dilaksanakan pada lingkungan pendidikan. Tidak hanya itu, buku teks merupakan buku acuan yang digunakan oleh pendidik dan siswa untuk memperlancar proses kegiatan belajar mengajar di sekolah.

Pendidikan nasional adalah pendidikan yang berdasarkan Pancasila dan UUD RI Tahun 1945 yang berakar pada nilai-nilai agama, kebudayaan nasional, dan tanggap terhadap tuntutan perubahan zaman. Tujuan Pendidikan Nasional Indonesia yang terdapat dalam Undang-Undang RI Nomor 20 Tahun 2003 tentang Sistem Pendidikan Nasional Bab 1 Pasal 1 ayat (1) mengatakan bahwa pendidikan adalah usaha sadar dan terencana untuk mewujudkan suasana belajar dan proses pembelajaran agar peserta didik secara aktif mengembangkan potensi dirinya untuk memiliki kekuatan spiritual keagamaan, pengendalian diri, akhlak mulia, serta keterampilan yang diperlukan dirinya, masyarakat, bangsa, dan negara (Rochmiyati, 2015:4).

Menurut kurikulum 2013, penyusunan buku teks harus memperhatikan beberapa kompetensi yang seharusnya diberikan untuk siswa. Buku teks bahasa 
Indonesia harus mengembangkan empat kompetensi anak yaitu sikap spiritual, sikap sosial, pengetahuan, dan keterampilan. Buku teks pada Kurikulum 2013 saat ini hanya mencakup kompetensi pengetahuan dan keterampilan. Sementara itu, pengembangan karakter yang meliputi sikap spiritual dan sikap sosial tidak terlalu diperhatikan.

Tujuan pendidikan taman siswa adalah membangun anak didik menjadi manusia yang beriman dan bertakwa kepada Tuhan Yang Maha Esa, merdeka lahir batin, luhur akal, cerdas dan berketerampilan, serta jasmani dan rohaninya untuk menjadi anggota masyarakat yang mandiri dan bertanggung jawab atas kesejahteraan bangsa, tanah air, serta manusia pada umumnya. Dalam sistem ini, pelaksanaan pendidikan lebih didasarkan pada minat dan potensi apa yang perlu dikembangkan pada anak didik, bukan pada minat dan kemampuan apa yang dimiliki oleh pendidik.

Menurut Prihatni (2014), konsep ajaran Ki Hadjar salah satunya yaitu Tri-N (Niteni, Nirokke, Nambahi). Niteni adalah menandai dengan memperhatikan secara saksama dan menggunakan seluruh pancaindra. Nirokke adalah menirukan apa yang diajarkan melalui model/contoh/teladan dari guru/sumber belajar dengan melibatkan pikiran, pengindraan , perasaan/ nurani, dan spiritual secara integral dan harmonis. Nambahi adalah menambah atau mengurangi apa yang telah dipelajarinya untuk mengembangkan kreativitas dan gagasannya dengan memanfaatkan sumber belajar yang ada.

Kemudian, menurut Sumiyati (2008), niteni berarti proses pencarian dan penemuan makna (sifat, ciri, prosedur, kebenaran) suatu objek amatan melalui suara indrawi. Nirokke dan nambahi berarti meniru dan mengembangkan/menambah. Perbedaan nirokke dan nambahi terletak pada kadar dan proses kreatifnya. Menurut Rahayu (2018), niteni berarti memperhatikan, mengamati, atau menyimak. Dalam hal ini peserta didik memperhatikan, melakukan pengamatan, membaca atau mendengarkan dengan teliti, meraba, dan merasakan dengan pancaindranya.

Melalui pengertian tersebut muncullah beberapa indikator proses niteni yaitu a) mengamati dengan menggunakan indra penglihatan, b) mengamati menggunakan indra pendengaran, c) mengamati menggunakan indra penciuman, 
d) mengamati menggunakan indra peraba, e) mengamati menggunakan indra pengecap f) menggali informasi lebih dalam dari hasil pengamatan, dan g) menalar dengan menghubungkan pengetahuan yang sudah dimiliki dari hasil galian. Indikator selanjutnya yaitu nirokke. Nirokke adalah menirukan apa yang diajarkan melalui model/contoh/teladan dari guru/sumber belajar dengan melibatkan pikiran pengindraan, perasaan/nurani dan spiritual secara integral dan harmonis. Proses nirokke yaitu: a) menirukan dengan melafalkan, b) menirukan dengan membaca, c) menirukan dengan menulis, d) menirukan dengan melalui gerakan, e) menirukan dengan mencoba/ eksperimen, f) menirukan dengan mendemonstrasikan/mempraktikkan, g) menirukan dengan menyajikan. Nambahi adalah menambah atau mengurangi apa yang telah dipelajarinya melalui model/contoh/teladan dari guru/sumber belajar dengan mengembangkan kreativitas dan gagasannya. Nambahi melalui proses yaitu: a) menambahi dengan mendesain, b) menambahi dengan mencipta/membuat, dan c) menambahi dengan mengimprovisasi. Begitu pentingnya konsep Tri-N dalam buku teks siswa, untuk itu dalam penelitian ini mencoba mendeskripsikan penerapan proses Tri-N yaitu Niteni, Nirokke, dan Nambahi pada buku teks siswa Bahasa Indonesia untuk Siswa SMP Kelas VIII Kurikulum 2013.

\section{B. Metode Penelitian}

Dalam penelitian ini menggunakan metode penelitian deskriptif kualitatif. Menurut Sugiyono (2015:15) penelitian kualitatif adalah metode yang berlandaskan filsafat postpositivisme, digunakan untuk meneliti pada kondisi obyek yang alamiah, (sebagai lawannya adalah eksperimen) dimana peneliti adalah sebagai instrumen kunci. Tujuannya yaitu untuk mendeskripsiakan penerapan proses niteni, penerapan proses nirokke, penerapan proses nambahi pada buku teks siswa bahasa Indonesia SMP Kelas VIII Kurikulum 2013. Waktu yang digunakan untuk menyelesaikan penelitian ini dimulai dari kajian referensi sampai proses pelaporan adalah enam bulan yaitu dimulai dari bulan Januari sampai Juni 2019. Penelitian ini diselesaikan dengan cara menelaah penerapan Tri-N (niteni, nirokke, nambahi) yang terdapat dalam buku siswa. 
Instrumen penelitiannya adalah peneliti sendiri yang sudah dibekali oleh seperangkat teori, kartu data, dan definisi operasional yang memuat telaah kata kerja operasional pada buku siswa. Instrumen tersebut kemudian telah divalidasi oleh pakar dalam pengajaran bahasa maupun pakar pada bidangnya.

Menurut Sangidu (2007: 73) analisis data bertujuan menyederhanakan data ke dalam bentuk yang lebih mudah dibaca dan diinterpretasikan. Model analisis yang digunakan yaitu model analisis interaktif Miles dan Huberman. Teknik analisis data pada penelitian ini yaitu diawali dengan mereduksi data, sajian data, dan verifikasi atau simpulan. Teknik keabsahan data yang dilakukan dengan membercheck dan memvalidasi instrumen oleh pakar yang selanjutnya dilakukan FGD (Focus Group Discussion).

\section{Hasil Penelitian dan Pembahasan}

\section{Hasil Penelitian}

Penerapan proses niteni pada indikator mengamati menggunakan indra penglihatan terdapat dalam semua bab I, II, III, IV, V, VI, VII, VIII, dan IX. Proses niteni pada indikator mengamati menggunakan indra pendengaran terdapat pada bab I, bab IV. Proses niteni pada indikator mengamati menggunakan indra penciuman tidak terdapat dalam semua bab. Proses niteni pada indikator mengamati menggunakan indra peraba tidak terdapat dalam semua bab. Proses niteni pada indikator mengamati menggunakan indra pengecap tidak terdapat dalam semua bab. Proses niteni pada indikator menggali informasi lebih dalam dari hasil pengamatan terdapat dalam semua bab. Proses niteni pada indikator menalar dengan menghubungkan pengetahuan yang sudah dimiliki dari hasil galian terdapat dalam semua bab.

Proses nirokke pada indikator menirukan dengan melafalkan melalui suara terdapat dalam bab II, IV, VI, dan IX. Proses nirokke pada indikator menirukan dengan membaca terdapat dalam bab I, II, III, IV, V, VI, VII, VIII, dan IX. Proses nirokke pada indikator menirukan dengan menulis terdapat dalab bab I, II, III, IV, V, VI, VII, VIII, dan IX. Proses nirokke pada indikator menirukan melalui gerakan terdapat dalam bab IX. Proses nirokke pada indikator menirukan dengan mencoba/eksperimen terdapat dalam bab III, V, VI, dan IX. Proses nirokke pada 
indikator menirukan dengan mendemonstrasikan/mempraktikkan terdapat dalam bab I, II, III, IV, V, VI, VII, VIII, dan IX. Proses nirokke pada indikator menirukan dengan menyajikan terdapat dalam bab I, II, III, IV, V, VI, VII, VIII, dan IX. Berdasarkan hasil telaah yang dilakukan oleh peneliti dalam buku siswa dapat ditemukan beberapa penerapan proses nirokke.

Penerapan proses nambahi dalam indikator yaitu: menambahi dengan mendesain tidak terdapat dalam bab I, II, III, IV, V, VI, VII, VIII, dan IX. Proses nambahi pada indikator menambahi dengan mencipta/membuat terdapat dalam bab I, II, III, IV, V, VI, VII, VIII, dan IX. Proses nambahi pada indikator menambahi dengan mengimprovisasi terdapat dalam bab II, III, IV, V, VI, VII, dan IX.

\section{Pembahasan}

Penerapan Tri-N berupa unsur niteni, nirokke, dan nambahi terdapat dalam buku teks siswa Bahasa Indonesia untuk Siswa SMP Kelas VIII Kurikulum 2013. Niteni dalam buku teks siswa terdapat unsur mengamati menggunakan indra pendengaran, menggali informasi lebih dalam dari hasil pengamatan, dan menalar dengan menghubungkan pengetahuan yang sudah dimiliki dari hasil galian. Nirokke dalam buku teks siswa terdapat unsur menirukan dengan melafalkan melalui suara, menirukan dengan membaca, menirukan dengan menulis, menirukan melalui gerakan, menirukan dengan mencoba atau eksperimen, menirukan dengan mendemonstrasikan atau mempraktikkan, dan menirukan dengan menyajikan. Kemudian, Nambahi dalam buku teks siswa terdapat unsur menambahi dengan mencipta atau membuat, dan proses menambahi dengan mengimprovisasi. Penerapan unsur Tri-N dalam buku teks ini sudah sesuai dengan konsep ajaran Ki Hadjar yang harus memiliki unsur Niteni, Nirokke, Nambahi (Prihatni, 2014).

Penerapan proses niteni, nirokke, dan nambahi pada buku teks siswa Bahasa Indonesia kelas VIII SMP Kurikulum 2013, dapat dijelaskan sebagai berikut. 


\section{a. Penerapan Proses Niteni}

Indikator niteni ada 7 yaitu pertama, mengamati menggunakan indra penglihatan. Berikut ini penerapan proses mengamati menggunakan indra penglihatan.

(1) Perhatikan cuplikan teks berikut ini! (Halaman 68)

"Sebelum itu, kondisi hutan Indonesia benar-benar sudah memprihatinkan.

Dalam kurun waktu 50 tahun, hutan Indonesia mengalami penurunan luas sebesar 64 juta hektare. Pembukaan hutan alam di dataran rendah di Sulawesi telah memusnahkan".

Pada kutipan (1) di atas merupakan perintah yang menuntut peserta didik untuk memperhatikan kutipan sebuah teks eksposisi yang terdapat pada buku. Peserta didik diharapkan dapat memperhatikan teks mengenai "Kondisi Hutan Indonesia".

Indikator kedua yaitu mengamati menggunakan indra pendengaran. Berikut ini penerapan proses mengamati menggunakan indra pendengaran.

(2) Mintalah seorang teman untuk membacakan berita berikut!

Dengarkan berita berikut dengan baik! Dengarkan berita berikut dengan baik! (Halaman 2)

Kutipan (2) di atas menguraikan penerapan proses niteni menggunakan indra pendengaran. Pada kutipan (2) merupakan sebuah perintah agar peserta didik dapat mendengarkan berita dari buku yang dibaca dan peserta didik dapat menyimak sebuah berita dari televisi/radio yang berkenaan dengan peristiwa alam. Peserta didik diharapkan dapat memahami dan mengerti apa yang disampaikan di dalam berita tersebut.

Indikator ketiga yaitu mengamati menggunakan indra penciuman. Pada buku siswa bahasa Indonesia Kelas VIII SMP Kurikulum 2013 tidak terdapat proses mengamati menggunakan indra penciuman. Selanjutnya, indikator keempat yaitu mengamati menggunakan indra peraba. Pada buku siswa bahasa Indonesia Kelas VIII SMP Kurikulum 2013 tidak terdapat proses mengamati menggunakan indra penciuman.

Indikator yang kelima yaitu mengamati menggunakan indra pengecap. Pada buku siswa bahasa Indonesia Kelas VIII SMP Kurikulum 2013 tidak terdapat proses mengamati menggunakan indra penciuman. Kemudian, indikator keenam 
yaitu menggali informasi lebih dalam dari hasil pengamatan. Berikut ini penerapan proses menggali informasi lebih dalam dari hasil pengamatan.

(3) Perhatikan kembali contoh teks ulasan novel "Atheis" di depan. Tampak bahwa struktur ataupun susunannya dibentuk oleh bagian-bagian seperti identitas karya, orientasi, sinopsis, analisis, dan evaluasi. (Halaman 166)

Kutipan (3) di atas menuntut peserta didik agar memperhatikan kembali dan menggali informasi lebih dalam dari hasil pengamatan berdasarkan novel "Atheis" dari segi identitas karya, orientasi, sinopsis, analisis, dan evaluasinya. Peserta didik diharapkan dapat mengerti isi atau makna dari sebuah novel "Atheis".

Indikator ketujuh yaitu menalar dengan menghubungkan pengetahuan yang sudah dimiliki dengan hasil galian. Berikut ini penerapan proses menalar dengan menghubungkan pengetahuan yang sudah dimiliki dengan hasil galian.

(4) Pada tugas sebelumnya, kamu telah banyak mendengarkan dan membaca banyak berita, bukan? Untuk tugas berikut, tentukan salah satu berita yang telah didengar atau dibaca. Kemudian, tentukanlah struktur dan kaidah-kaidah kebahasaannya. (Halaman 18)

Kutipan (4) menuntut peserta didik untuk menentukan struktur dan kaidahkaidah kebahasaan yang terdapat di dalam teks. Sebelum menentukan struktur dan kaidah-kaidah kebahasaan, peserta didik telah mendengarkan dan membaca berbagai macam berita.

\section{b. Penerapan Proses Nirokke}

Indikator nirokke 7 yaitu pertama, menirukan dengan melafalkan/ melalui suara. Berikut ini penerapan proses menirukan dengan melafalkan/melalui suara.

(5) Secara berdiskusi, ceritakan kembali isi iklan-iklan berikut!

Kutipan (5) dan menuntut peserta didik untuk melafalkan atau menirukan melalui suara. Kutipan (5) menuntut peserta didik untuk menceritakan kembali isi iklan-iklan yang terdapat dalam buku siswa secara berkelompok.

Indikator yang kedua yaitu menirukan dengan membaca. Berikut contoh kutipan proses menirukan dengan membaca. Berikut ini merupakan penerpan proses menirukan dengan membaca. 
(6) Bacakan kesimpulan itu di depan teman-temanmu. Kemudian, mintalah mereka untuk memberikan tanggapan berdasarkan kelogisan atau kesesuainnya dengan informasi awal. (Halaman 9)

Kutipan (6) menuntut peserta didik untuk membacakan sebuah kesimpulan dari bacaan yang terdapat dalam buku siswa. Kemudian, peserta didik meminta agar teman-teman yang lain untuk memberikan tanggapan berdasarkan kelogisan atau kesesuaiannya dengan informasi bacaan awal.

Indikator yang kedua yaitu menirukan dengan menulis. Berikut ini merupakan penerapan proses menirukan dengan menulis.

(7) Catatlah pokok-pokok informasinya. Kemudian, tulislah tanggapan.

Anda berkenaan dengan informasi tersebut, baik itu berkenaan dengan

isi/struktur maupun penggunaan bahasanya. (Halaman 12)

Kutipan (7) menuntut peserta didik agar mencatat informasi-informasi penting yang terdapat pada bacaan. Kutipan (7) menuntut peserta didik agar mencatat pokok-pokok informasi. Kemudian, menuliskan tanggapan yang berkenaan dengan informasi bacaan.

Indikator keempat yaitu, menirukan melalui gerakan. Berikut ini contoh penerapan proses menirukan melalui gerakan.

(8) Gerakan tatapan mata dengan mengikuti titik-titik hitam itu secara cepat. (Halaman 243)

Kutipan (8) menuntut peserta didik untuk melakukan suatu gerakan mata. Kutipan (8) menuntut peserta didik agar menggerakkan tatapan mata dengan mengikuti titik-titik hitam secara cepat pada buku.

Indikator kelima yaitu menirukan dengan mencoba/eksperimen. Berikut ini contoh penerapan proses menirukan dengan mencoba/eksperimen.

(9) Buktikan, berdasarkan kaidah-kaidah kebahasaannya bahwa cuplikancuplikan teks di bawah ini merupakan bagian dari teks eksplanasi! Lakukan secara berkelompok. (Halaman 146-147)

Kutipan (9) menuntut peserta didik untuk melakukan percobaan atau eksperimen. Kutipan (9) menuntut peserta didik beserta kelompok untuk membuktikan berdasarkan kaidah-kaidah kebahasaannya bahwa cuplikancuplikan teks di bawah ini merupakan bagian dari teks eksplanasi. 
Indikator keenam yaitu menirukan dengan mendemonstrasikan/ mempraktikkan. Berikut ini contoh penerapan proses menirukan dengan mendemonstrasikan.

(10) Presentasikanlah pendapat kemlompokmu itu di depan kelompok lainnya untuk mendapatkan tanggapan-tanggapan berdasarkan kelengkapan, ketepatan, dan kejelasan penyampaiannya. (Halaman 190-191)

Kutipan (10) menuntut peserta didik untuk membuat kesimpulan/ pendapat kelompok yang telah dikerjakan secara bersama, kemudian dipresentasikan di depan kelompok lain untuk mendapatkan tanggapan-tanggapan berdasarkan kelengkapan, ketepatan, dan kejelasan penyampaiannya.

Indikator ketujuh yaitu menirukan dengan menyajikan. Berikut ini contoh penerapan proses menirukan dengan menyajikan.

(11) a) (Baca) atau dengarkan sekurang-kurangnya lima berita dari media cetak atau elektronik!

b) Catatlah sumber, tanggal pemberitaan, dan isi pokok berita-berita tersebut!

c) Sajikan hasil kegiatanmu itu dalam format laporan berikut. (Halaman 6)

Kutipan (11) merupakan perintah yang menuntut peserta didik agar menyajikan sebuah hasil suatu pekerjaan atau tugas yang terdapat dalam buku. Kutipan (11) menuntut peserta didik untuk menyajikan hasil kegiatan sesuai dengan format yang sudah ditentukan.

\section{c. Penerapan Proses Nambahi}

Indikator nambahi ada 3 yaitu pertama, menambahi dengan mendesain. Pada buku teks Bahasa Indonesia Kelas VIII SMP Kurikulum 2013 tidak terdapat penerapan proses menambahi dengan mendesain. Indikator kedua yaitu menambahi dengan mencipta/membuat. Berikut ini contoh penerapan proses menambahi dengan mencipta/ membuat.

(12) a) Peristiwa manakah yang layak diberitakan? Susunlah dari yang terpenting ke yang kurang penting dengan membubuhkan nomor pada kotak yang tersedia!

b) Misalnya, kamu akan membuat berita tentang pementasan drama yang dilakukan oleh kelompok teater di sekolah. Bagaimana pertanyaan-pertanyaan yang akan kamu ajukan kepada pemimpin dan anggota teater tersebut?

c)Tulislah sebuah berita dengan peristiwa yang kamu tentukan sendiri! (Halaman 21) 
Kutipan (12) menuntut peserta didik untuk membuat sebuah tulisan yaitu sebuah berita dengan peristiwa yang telah ditentukan sendiri oleh anak. Kutipan (12) peserta didik diharapkan mampu membuat sebuah berita sesuai dengan kejadian dan kemampuan anak dalam mengembangkan sebuah berita.

Indikator ketiga yaitu menambahi dengan mengimprovisasi. Berikut ini contoh penerapan proses menambahi dengan mengimprovisasi.

(13) Lengkapilah tabel di bawah ini dengan benar sesuai dengan tingkat penguasaanmu terhadap materi-materi dalam bab ini! (Halaman (197)

Kutipan (13) merupakan perintah yang menuntut peserta didik untuk mengimprovisasi. Kutipan (13) menuntut peserta didik untuk melengkapi sebuah tabel yang terdapat dalam buku siswa dengan benar, sesuai tingkat penguasaan masing-masing peserta didik ketika belajar materi tersebut.

\section{Simpulan}

Berdasarkan hasil penelitian dan pembahasan dapat disimpulkan bahwa semua indikator proses niteni, nirokke, dan nambahi terdapat dalam buku teks siswa Bahasa Indonesia untuk Siswa SMP Kelas VIII Kurikulum 2013. Niteni dalam buku teks siswa terdapat unsur mengamati menggunakan indra pendengaran, menggali informasi lebih dalam dari hasil pengamatan, dan menalar dengan menghubungkan pengetahuan yang sudah dimiliki dari hasil galian. Unsur Nirokke dalam buku teks siswa terdapat unsur menirukan dengan melafalkan melalui suara, menirukan dengan membaca, menirukan dengan menulis, menirukan melalui gerakan, menirukan dengan mencoba atau eksperimen, menirukan dengan mendemonstrasikan atau mempraktikkan, dan menirukan dengan menyajikan. Kemudian, Nambahi dalam buku teks siswa terdapat unsur menambahi dengan mencipta atau membuat, dan proses menambahi dengan mengimprovisasi. Hasil penelitian ini menunjukkan bahwa buku teks siswa Bahasa Indonesia untuk Siswa SMP Kelas VIII Kurikulum 2013 layak digunakan sebagai salah satu bahan ajar bahasa Indonesia di sekolah karena memiliki unsur Tri-N yaitu niteni, nirokke, dan nambahi. 


\section{Daftar Pustaka}

Haslinda, H. (2017). Pengembangan Bahan Ajar Kajian Apresiasi Prosa Fiksi Berbasis Kearifan Lokal Terintegrasi Mobile Learning. Konfiks: Jurnal Bahasa dan Sastra Indonesia, 4(1), 48. doi:10.26618/jk.v4i1.1216

Noermanzah \& Friantary, H. (2019). Development of Competency-Based Poetry Learning Materials for Class $\mathrm{X}$ High Schools. International Journal of Recent Technology and Engineering, 8 (4).

Noermanzah, N. (2015). Peran Dosen Bahasa dan Sastra Indonesia dalam Mempertahankan Bahasa Indonesia sebagai Alat Pemersatu Negara Kesatuan Republik Indonesia pada Era Globalisasi. Dalam Prosiding Seminar Nasional Bulan Bahasa 2015. Unit Penerbitan FKIP Universitas Bengkulu, p. 274. http://repository.unib.ac.id/11133/

Nugroho, A., \& Fitri, L. (2018). Respons Siswa SMP Negeri se Kota Lubuklinggau terhadap Bahan Ajar Cerita Rakyat Lubuklingau. Silampari Bisa: Jurnal Penelitian Pendidikan Bahasa Indonesia, Daerah, dan Asing, 1(1), 117. doi:10.31540/silamparibisa.v1i1.11

Prihatni, Yuli. (2014). "Pendekatan Saintifik dalam Ajaran Ki Hadjar Dewantara". Prosiding Seminar Nasional Pendidikan Sains. (Vol. 2 Nomor 1). HIm. 290300.

Rahayu, Indah. (2018). “ Penerapan Konsep 3N (Niteni, Nirokke, Nambahi) untuk Meningkatkan Motivasi Belajar Matematika Siswa”. Prosiding Seminar Nasional Etnomatsia.

Rochmiyati, Siti. (2015). "Kebijakan Pendidikan Bahasa Indonesia dalam Perspektif Pendidikan Nasional”. CARAKA, 1 (2), 3-13.

Sangidu. (2017). Penelitian Sastra: Penelitian Sastra: Pendekatan, Teori, Metode, Teknik, dan Kiat. Yogyakarta: Seksi Penerbitan Sastra Asia Barat Fakultas IImu Budaya UGM.

Sugiyono. (2015). Metode Penelitian Pendidikan Pendekatan Kualitatif dan R\&D. Bandung: Alfabeta.

Sumiyati. 2018. "Pengaruh Konsep 3N 'Niteni, Nirokke, Nambahi' terhadap Prestasi Belajar Matematika Ditinjau dari Keaktifan Siswa Kelas X SMK". Prosiding Seminar Nasional Etnomatsia.

Undang-Undang RI Nomor 20 Tahun 2003 tentang Sistem Pendidikan Nasional Bab 1 Pasal 1. 